\title{
Labor Productivity as a Factor for Increasing Public Production Efficiency
}

\author{
Polovkina E. A. \\ Kazan Federal University, Institute of Management, Economics and Finance, Kazan, 420008, Russia \\ Email address: eapol62@mail.ru \\ Badrieva L. D. \\ Kazan Federal University, Institute of Management, Economics and Finance, Kazan, 420008, Russia
}

\section{Doi:10.5901/mjss.2014.v5n24p366}

\begin{abstract}
The article focuses on an integral estimation of the public production effectiveness and shows the role of human labor productivity in the formation of the summarizing performance indicator. It focuses on measuring the public production effectiveness. The role of labor productivity as a major criterion of the efficiency of the national economy is shown. The problem of measuring the public production effectiveness is inseparable from the problem of measuring productivity. The aim of this study is to identify minimum indicators that characterize the public production efficiency and which make up a balanced system. To search for a balanced system the study uses: the traditional scheme of resource expressions for integral indicator of the public production effectiveness, including labor resources, production capital and working capital; integral estimation of the public production effectiveness, including labor productivity, return on fixed capital stock; return on stocks; after receiving a list of factors for integral estimation of the efficiency of production, procedure for calculating the multivariate average value of production resources is used in order to identify the role of human labor productivity and other factor variables in the summarizing performance indicator. Quantitative analysis of factors for integral expression of regional effectiveness of public production under the conditions of each individual unit of the territorial system can be accomplished by methods of the index factor analysis. As for the application to the whole territorial system, taking into account the statistical nature of the dependencies studied it is appropriate to use correlation - regression and multivariate analyzes, which make it possible to pose the problem in matrix form, and therefore they are adequately relevant to the content of system approach. The results of the analysis are mostly characteristic of engineering. In other industries, there is specificity in the distribution of the weighted coefficients of the performance indicators used in the manufacturing process of certain types of resources.
\end{abstract}

Keywords: Labor productivity, efficiency, correlation and regression analysis, efficiency factors, multivariate analysis.

\section{Introduction}

Labor productivity as a phenomenon in economic life is interrelated to other economic relations, events and processes [Abalkin, 1987; Polovkina, 2012]. On the one hand, the productivity is influenced by many factors of the economy, and on the other hand, it has a direct or indirect impact on many socio-economic phenomena and processes [Sokolova, 2000]. This relationship may be both direct and inverse [Khromov, 1979].

It should be noted that the labor productivity increase is the most important factor in the growth of public production and economic dynamics rate under the current socio-economic conditions [Leontiev, 1990; Shigabutdinova, 2013]. For centuries international practice has been showing a direct relationship between labor productivity in any national economy and its level of socio - economic development [Spiegel, 2014; Suhartono, 2011].

In the literature about the measurement of the production efficiency, a number of authors consider the total public labor as one of the performance criteria at the national level [Celin, 2002; Kendrick, 1984]. From this it is clear that one of the decisive factors in the efficiency of public production is the labor productivity, as the latter is a part of the total labor costs [Smirnov, 2003; Smirnov, 2010].

In economics it is known that a wide range of indicators characterize the efficiency of using those resources in the production which are, by their nature, a conglomeration of materialized labor, but it is difficult to select a certain minimum from their number, as they constitute a balanced system with the labor productivity, rather than a mechanical set of attributes [Sink, 1989].

The problem of connecting labor and material resources into a single result, can be solved by converting material resources in labor, rather than converting the labor force in the material one [Odegov, 2011]. To search for a balanced 
system the study uses:

1. traditional scheme for resource expression of integral indicator of the public production effectiveness, including the human labor resources, production capital and working capital;

2. integral estimation of the of public production effectiveness, including labor productivity, return on fixed capital stock; return on stocks.

3. After receiving a list of factors for integral estimation of the production efficiency, procedure for calculating the multivariate average value of production resources is used, in order to identify the role of human labor productivity and other factor variables in the summarizing performance indicator.

\section{Research Methods}

The traditional scheme for resource expressions of integral indicator of the public production effectiveness is as follows:

$$
B e=\frac{E}{L+A+S}
$$

where $B_{\mathrm{e}}$ - beneficial effect of production (gross output);

$L$ - human labor resources used;

A - capital assets;

S - stocks.

Connecting labor and material resources in a single result can be achieved by converting material resources into labor. To do this, the cost of capital assets and stocks is divided by labor productivity and thus we get the number of workers needed for the reproduction of value which is equivalent to the cost of industry production facilities in the economy of the region, during the calendar year, depending on the progress in labor performance rate in the region:

$$
\mathrm{Be}=\frac{E}{E+\left(\frac{A}{E}\right): L+\left(\frac{S}{E}\right): L}
$$

Let's make some transformations of formula (2) in order to differentiate its constituent components:

$\mathrm{B}_{\mathrm{e}}=\frac{E}{L+\frac{A^{*} L}{E}+\frac{S^{*} L}{E}}=\frac{E}{\frac{L^{*} E+A^{*} L+S^{*} L}{E}}=\frac{E^{*} E}{L(E+A+S)}=\frac{E}{L} * \frac{E}{E+A+S}$

Thus, we obtain another proof of the fact that the human labor productivity $(E / L)$ is an algebraic sum of integral estimation of the public production effectiveness.

In order to obtain the other variables which make up integral estimation, we make a further transformation of the right factor of formula (3), and divide its numerator and denominator by the number of useful effect:

$$
\mathrm{B}_{\mathrm{e}}=\text { Labor productivity }{ }^{*}+\frac{1}{1+\frac{A}{E}+\frac{S}{E}}=\frac{\text { laborproductivity }}{1+\frac{1}{E: A}+\frac{1}{E: S}} \text {. }
$$

Consequently, the integral estimation of the public production effectiveness can be expressed as a result of the interaction of three variables;

$$
B e=\frac{x_{1}}{1+\frac{1}{x_{2}}+\frac{1}{x_{3}}}
$$

or in a more general type:

$$
B e=f\left(x_{1}, x_{2}, x_{3}\right) \text {, }
$$

where $\mathrm{x}_{1}$ - labor productivity

$x_{2}$ - return on capital assets;

$x_{3}-$ return on stocks.

The denominator of the integral estimation can also be represented as capital intensity indicators of production and velocity of working capital, but the essence remains the same.

The economic meaning of the denominator of formula (4) is that it is a coefficient that characterizes the number of times the total labor costs exceeds the costs of living labor, hence it can be used in economic analysis and is directly related to the integral estimation of the effectiveness.

After receiving the list of factors integral evaluation of the production efficiency, it is necessary to establish the role of human labor productivity and other factor variables in the formation of the summarizing efficiency indicator, as well as how individual factor attributes interact with each other.

Quantitative factor analysis of integral expression of regional public production effectiveness under the conditions 
of each individual unit of the territorial system can be accomplished by methods of the index factor analysis. As for the application to the whole territorial system, taking into account the statistical nature of the investigated dependencies it is appropriate to apply correlation - regression and multivariate analyzes which make it possible to pose the problem in matrix form, and therefore they are adequately relevant to the content of system approach. Integral estimation of the public production effectiveness is calculated based on formula (1), presenting its denominator as a multivariate average of individual types of productive resources.

The mechanism of multivariate averages uses standardized assessment of averaged variables of multivariate analysis.

$$
P_{i j}=\frac{x_{i j}}{x_{i}},
$$

where $i=1,2,3$ - the type of production resources;

$\mathrm{j}=1,2,3, \ldots, \mathrm{N}$ - economic regions.

The advantage of multivariate averages in comparison with the methods of component and factor analysis is a more active nature of search of multidimensional quantity, and to a much greater extent, the role of content analysis which is conducted at the first stage of the study is increasing. In this problem, a multivariate assessment will show how much production resources are available for an average industry of economic regions.

However, different types of resources do not play the same role in the formation of beneficial effect. Consequently, the multivariate average should be weighted quantity. As weights we have taken partial coefficients of determination that characterize a measure of the variations effect of each type of resource on the formation of the gross output of the industry when abstracting from the effects of variations of other types of resources:

$d_{i}=r_{y x i} \beta_{i}$,

where $r_{y x i}$ - correlation coefficient between the value of gross output and production resources; $\beta_{i}$ - equation coefficients of multiregression in the standardized scale.

\section{Discussion}

Russian and foreign scholars are continuing research in the productivity methodology in current economic situation [Andreyeva, 2013; Belyaeva., 2012; Solow, 1957].

Professor A. Zolotov, Doctor of Economics, for example, rightly believes that "the problem of increasing labor productivity has not objectively lost its paramount importance though it was pushed into the background in the first years of reforms » [Zolotov, 2002]. The author argues that the postulates of economics, which have become widespread recently, do not separate productive labor from other types of useful activities. This is not surprising, if labor is defined as any mental and physical effort undertaken partially or entirely in order to achieve any result, aside from satisfaction, obtained directly from the work done.

When analyzing existing approaches of statistical investigation to labor productivity we found that Russian economists have no single methodology to study this category [Basovskaya, 2013; Gagarinsky, 2013]. It is objective in nature, as productivity is a complex, multidimensional concept of economic science. In order to reveal the essence of the economic analysis of labor productivity, it is necessary to highlight the main aspects of the study. Thus, S. Fabrikant, an American economist, writes that "... labor productivity, anyway, is an integral part of any broad economic problem, whether industrialization or research and development, automation or tax reform, the disparity between prices and cost, inflation or currency shortage "[Barysheva, 1999].

In addition, some economists propose to distinguish between the concept of "productivity" and "labor productivity" because these categories have different meanings. L. Sokolova, in our view, rightly believes that "productivity" as an economic category in its content is much broader than "labor productivity" because productivity can be considered in relation to all factors of production and to each of them separately [Sokolova, 2000 , Sokolova, 2002]. Labour productivity is characterized by the use of human labor (labor forces) and is determined by the productive power of labor and the labor intensity [Farzianpour, 2011].

An interesting approach was proposed by M. Porter, Harvard Business School professor, who comes from the fact that the main goal of each state is to achieve a high and constantly rising standard of living for its citizens, and the possibility of its implementation depends on the productivity which is achieved by the use of labor and capital. "The only sensible concept of competitiveness at the national level is productivity, that is, the volume of output produced by a unit of labor input and capital» [Porter, 2000]. According to M. Porter's theory, labor and capital productivity, along with the living standard of a nation define the basic parameters of its competitiveness. 
Summarizing the above-said, we should note that labor productivity as a category of economic science is determined by the development level of the productive forces in society and is characterized by the appropriate production relations [Sumenth, 1986]. In this context, the problem of increasing labor productivity should be considered as cumulative saving of living and materialized labor.

\section{The Results of the Study}

Calculations showed that in the conditions analyzed, variation of gross output by $60.1 \%$ is determined by the variation of the number of industrial and production staff $\left(x_{1}\right)$, by $20 \%$ - the variation of fixed assets $\left(x_{2}\right)$ and by $10 \%$ - the variation of the value of stocks $\left(\mathrm{x}_{3}\right)$.

Thus, the procedure of calculating multivariate average of industrial resources may be described by the formula: $P_{j}=\frac{\sum P_{i 1} d_{i}}{\sum d_{i}}$

The calculation result of the integral estimation of production resources is characterized by data in column 8 of Table 1. They mean that the first of the considered economic regions has manufacturing resources that make up $341.9 \%$ compared to the average inter-district, second region - 102, third, 63.9, etc.

Integral estimation of the production efficiency is the ratio of the standardized value of the beneficial effect $-y_{i} / y$ to an integral estimation of productive resources. Its values (see column 10) should also be interpreted as a relative value that characterizes the measure of use efficiency of all resources in the manufacturing process that is expressed as a percentage of inter-district level [Rangelova, 2013].

The integral estimation of the production efficiency and of its components makes it possible to calculate the parameters of formula (5) based on the correlation and regression framework. However, interesting are not only the equation coefficients of multiregression in natural scale, but also characteristics derived from them that set the priority of factor variables and, therefore, give the key to the solution of this problem [Ayinde, 2007; . Azadeh, 2005].

In general, the nature of the relationships in the integral estimation of the production effectiveness and its determinants is clearly expressed by paired correlation matrix (Table 2).

Table 1. Calculation of integral estimations of productive resources and production effectiveness by industries output of economic regions (numbers are relative)

\begin{tabular}{|c|c|c|c|c|c|c|c|c|c|c|}
\hline $\begin{array}{c}\text { Economic } \\
\text { regions }\end{array}$ & $P_{1 j}=\frac{x_{1 j}}{x_{1}}$ & $P_{2 j}=\frac{x_{2 j}}{x_{2}}$ & $P_{3 j}=\frac{x_{3 j}}{x_{3}}$ & $\begin{array}{c}\mathrm{P}_{1 j} \\
0,6107\end{array}$ & $\begin{array}{c}\mathrm{P}_{2 j} \\
0,2002\end{array}$ & $\begin{array}{c}\mathrm{P}_{3 j} \\
0,1002\end{array}$ & $\sum P_{i j} * d_{i}$ & $\frac{\sum P_{i j} d_{i j}}{\sum d_{i}}$ & $\frac{y_{j}}{y}$ & $\begin{array}{c}\text { Integral } \\
\text { estimation of } \\
\text { production } \\
\text { effectiveness }\end{array}$ \\
\hline & 1 & 2 & 3 & 4 & 5 & 6 & $7=4+5+6$ & 8 & 9 & $10=9: 8$ \\
\hline 1 & 3,779 & 2,919 & 2,226 & 2,308 & 0,584 & 0,223 & 3,115 & 3,419 & 2,485 & 0,727 \\
\hline 2 & 1,143 & 0,810 & 0,991 & 0,698 & 0,162 & 0,069 & 0,929 & 1,020 & 1,248 & 1,224 \\
\hline 3 & 0,700 & 0,429 & 0,684 & 0,427 & 0,086 & 0,069 & 0,582 & 0,639 & 0,976 & 1,527 \\
\hline 4 & 0,341 & 0,403 & 0,579 & 0,227 & 0,081 & 0,058 & 0,366 & 0,402 & 0,593 & 1,475 \\
\hline 5 & 1,057 & 1,226 & 1,677 & 0,646 & 0,245 & 0,168 & 1,059 & 1,162 & 0,979 & 0,843 \\
\hline 6 & 0,336 & 0,483 & 0,512 & 0,205 & 0,097 & 0,051 & 0,353 & 0,387 & 0,311 & 0,804 \\
\hline 7 & 1,565 & 1,925 & 1,422 & 0,956 & 0,385 & 0,142 & 1,483 & 1,628 & 1,526 & 0,937 \\
\hline 8 & 1,113 & 1,799 & 1,779 & 0,680 & 0,360 & 0,178 & 1,218 & 1,336 & 1,300 & 0,973 \\
\hline 9 & 0,447 & 0,529 & 0,532 & 0,273 & 0,106 & 0,053 & 0,432 & 0,474 & 0,755 & 1,593 \\
\hline 10 & 0,331 & 0,261 & 0,419 & 0,202 & 0,052 & 0,042 & 0,296 & 0,325 & 0,336 & 1,034 \\
\hline 11 & 0,434 & 0,369 & 0,368 & 0,265 & 0,074 & 0,037 & 0,376 & 0,413 & 0,416 & 1,007 \\
\hline 12 & 0,724 & 0,848 & 1,112 & 0,442 & 0,170 & 0,111 & 0,723 & 0,794 & 1,077 & 1,356 \\
\hline
\end{tabular}

Paired $r_{y x i}$ coefficients show that the level of production efficiency is associated most closely with the human labor productivity. The interaction mechanism of factor variables is characterized by $\mathrm{r}_{\mathrm{x} i}$ coefficients.

Partial elasticity coefficients, calculated to assess the priority of factor attributes, showed that with the increase in labor productivity by $1 \%$ integral indicator of regional production efficiency will increase by $0.935 \%$, a similar measure of growth in capital productivity and return on stocks causes an increase in the dependent variable by 0.230 and $0.150 \%$ respectively. 
Table 2. Matrix of paired correlation coefficients of statistical model for integral indicator of public production effectiveness in industries output of economic regions

\begin{tabular}{|l|c|c|c|c|}
\hline Indicator & $r_{y x_{i}}$ & $r_{x_{1}}$ & $r_{x_{2}}$ & $r_{x_{3}}$ \\
\hline Integral indicator of regional production effectiveness $(\mathrm{y})$ & 1 & & & \\
\hline Labor productivity $\left(\mathrm{x}_{1}\right)$ & 0,9369 & 1 & & \\
\hline Capital productivity $\left(\mathrm{x}_{2}\right)$ & 0,6843 & 0,4860 & 1 & \\
\hline Return on stocks & 0,4112 & 0,1568 & 0,5876 & 1 \\
\hline
\end{tabular}

However, partial elasticity coefficients still have more limited cognitive value in comparison with partial coefficients of determination, since they take into account only the intensity of the effect of changes in factor variables on the dependent variable, but do not take into account the limits of the influence [Krasnopevtseva, 2013]. Partial coefficients of determination, free from this defect, showed that regional production efficiency by $76 \%$ is determined by the variation in labor productivity, by $13.7 \%$ - a variation of capital production, and by $7.5 \%$ - a variation of return on stocks. Consequently, in a regional economy increase in labour productivity is ultimately a decisive factor in growth of production efficiency.

\section{Conclusion}

The weighted coefficients thus obtained explain how increase in the production efficiency can be achieved while reducing the return on assets.

In order to verify the effectiveness of particular organizational - technical activities, it is necessary to fulfill a stipulation: to some extent, product of human labor productivity indicator and its calculated weighted coefficient should exceed the product of capital productivity decrease and respective weight.

The results of the analysis are most characteristic of engineering [Garshina, 2013]. In other industries, there is specificity in the distribution of the weighted coefficients with the performance indicators of the use of certain types of resources in the manufacturing process. In the oil-refining industry the nature of fixed assets plays an increased role in shaping the production efficiency, due to the high capital intensity of production, and in the tire industry - the use of stocks.

The problem of measuring public production effectiveness is inseparable from the problem of measuring labor productivity. On its basis, the best ways to increase the development efficiency of regional economy and its individual sectors are determined, in particular with a different dynamics of labor productivity and return on capital stock and working capital, the intensity of plans is measured, and some other economic and planning and economic-statistical problems are solved.

\section{References}

Abalkin L.I., 1987. Social labor productivity: nature, role, growth factors, ed. L.I. Abalkin, Moscow, Mysl.

Andreyeva, E.L., Polkova, T.V., 2013. The estimation of labor life quality in regions of Russia. Economy of Region, 3: 91-100.

Ayinde, K., 2007. A Comparative Study of the Performances of the OLS and some GLS Estimators when Stochastic Regressors are both Collinear and Correlated with Error Terms. J. Math. Stat., 3: 196-200.

Azadeh, A., J. Nouri and I.M. Fam, 2005. The Impacts of Total System Design Factors on Human Performance in Power Plants. Am. J. Applied Sci., 2: 1301-1304.

Barysheva A.V., 1999. Labour productivity in the developed capitalist countries, Moscow, Nauka.

Basovskaya E.N., 2013. The main factors of productivity and wages in modern Russia. Scientific research and development. Economy, 2 (2): $3-10$.

Belyaeva E.S., Markina S.A., 2012. Current approaches to solving problems of increasing productivity. Proceedings of the Southwest State University. Series: economics, sociology, management, 1:40-47.

Celin E.N., 2002. Labor productivity: methodology for determining and reserves of growth. St. Petersburg Agropromizdat.

Farzianpour, F., A.R. Fouroshani, R.G. Vahidi, M. Arab and A. Mohamadi, 2011. Investigating the relationship between organizational social capital and service quality in teaching hospitals. Am. J. Econ. Bus. Admin., 3: 425-429.

Gagarinsky A.V., 2013. Methodological support of management process of working efficiency in an industrial plant . Kazanskaya nauka, 8:13-17.

Garshina O.P., 2013. Ways of increasing productivity in machine-building enterprises. Bulletin of the Samara State University, 1 (102): pp.164-170 . 
Kendrick J., 1984. Improving company productivity. Baltimore, The Johns Hopkins University Press.

Khromov P.A., 1979. Labor productivity (theory, methodology, dynamics), Moscow, Nauka.

Krasnopevtseva I.V., 2013. Mathematical modeling of the impact of organizational factors on the level of productivity of industrial workers. Herald VSGUTU, 3 (42): 80-86.

Leontiev V., 1990. Economic essays. Theory, research, facts and policy: Trans. from English, Moscow, Politizdat.

Odegov Yu.G., Sidorov V.N. 2011. Modern problems of working time and productivity growth. Rationing and wages in industry, 4: 21-24.

Polovkina E.A. Theoretical models of relationships between employment and labor productivity. //Journal. "Intellect.Innovatsii.Investitsii" Part 1. 2012. P. 158-160.

Porter M. Competition. - S.Petersburg., 2000, p. 168.

Rangelova, R., 2013. Empirical analysis of the interconnection between structural changes and labour productivity. Ikonomicheski Izsledvania, 22 (1): 3-40.

Shigabutdinova A.F., 2013. Productivity growth as a factor of increasing the competitiveness of the domestic petrochemical complex. Intellekt . Innovation. Investments in 2013, 2, pp 56-61.

Sink D.S., 1989. Productivity management: planning, measurement and evaluation, control and improvement: Trans. from English, Moscow, Progress.

Smirnov V.S., 2003. Bourgeois production organism, theory and methodology, Moscow, Dashkov i K.

Smirnov V.S., 2010. Bourgeois production organism: Theory and Methodology, Moscow, Nayka.

Sokolova L.G., 2000. Productivity: theory, measurement, growth problems. Irkutsk, IGEA.

Sokolova L.G., 2002. New look at productivity: assessment methodology of overall productivity. Irkutsk BSUEL.

Solow R.W., 1957. Technical change and aggregate production function. The Review of Economics and Statistics, 8: 12-16.

Spiegel, U., Gonen, L.D., Weber, M. 2014. Duration and optimal number of shifts in the labour market. Applied Economics Letters, 21 (6): 429-432

Suhartono, 2011. Time Series forecasting by using seasonal autoregressive integrated moving average: subset, multiplicative or additive model. J. Math. Stat., 7: 20-27.

Sumenth D.J., 1986 Productivity Engineering and Management. New York: McGrow - Hill Book Company

Zolotov A., 2002. Social productivity, Economist, 6.

Suhartono, 2011. Time Series forecasting by using seasonal autoregressive integrated moving average: subset, multiplicative or additive model. J. Math. Stat., 7: 20-27.

Sumenth D.J., 1986 Productivity Engineering and Management. New York: McGrow - Hill Book Company

Zolotov A., 2002. Social productivity, Economist, 6. 